\title{
Clinical significance of accurate identification of lymph node status in distant metastatic gastric cancer
}

\author{
Rui Zhou ${ }^{1, *}$, Zhenzhen $\mathrm{Wu}^{1, *}$, Jingwen Zhang ${ }^{1}$, Hongqiang Wang ${ }^{1,2}$, Yuqi $\mathrm{Su}^{1,3}$, \\ Na Huang ${ }^{1}$, Min Shi ${ }^{1}$, Jianping Bin ${ }^{4}$, Yulin Liao ${ }^{4}$, Wangjun Liao ${ }^{1}$ \\ ${ }^{1}$ Department of Oncology, Nanfang Hospital, Southern Medical University, Guangzhou 510515, China \\ ${ }^{2}$ Department of Oncology, Zhoushan Hospital, Zhoushan 316000, China \\ ${ }^{3}$ Department of Oncology, The First People's Hospital of Yueyang, Yueyang 414000, China \\ ${ }^{4}$ Department of Cardiology, Nanfang Hospital, Southern Medical University, Guangzhou 510515, China \\ *These authors have contributed equally to this work \\ Correspondence to: \\ Wangjun Liao, e-mail: nfyyliaowj@163.com \\ Keywords: lymph node status, palliative surgery, LND, distant metastatic gastric cancer, survival \\ Received: August 14, $2015 \quad$ Accepted: October 09, $2015 \quad$ Published: October 19, 2015
}

\section{ABSTRACT}

PURPOSE: The clinical consequences of accurately identifying lymph node (LN) status in distant metastatic gastric cancer (DMGC) are unclear. We aimed to determine the prognostic significance of $\mathbf{N}$ stage, positive LN (PLN) count, and the positive LN ratio (LNR). We also retrospectively compared survival outcomes of DMGC patients stratified by LN dissection (LND).

RESULTS: LND was performed in 1593 patients. The CSS was significantly different between groups divided according to $\mathrm{N}$ stage, PLN, and LNR in DMGC patients who underwent LND. Lower LNR was an independent predictor of longer survival in all kinds of patients cohorts, whereas PLN was not such a predictor. PLN count correlated with LND number and LNR. No correlation existed between LNR and LND number. Undergoing LND and having a higher number of dissected LNs were associated with superior CSS.

MATERIALS AND METHODS: Data from 1889 DMGC patients treated between 2004 and 2009, and documented in the Surveillance, Epidemiology, and End Results (SEER) registry, were reviewed. Pearson's correlation coefficient and the Chi-square test were used to study the relationships between LND number, PLN count, $\mathbf{N}$ stage, and the LNR. Cancer-specific survival (CSS) was evaluated using Kaplan-Meier analysis, with the log-rank test performed for univariate analysis (UVA) and the Cox proportional hazards model employed for multivariate analysis (MVA).

CONCLUSION: LN metastatic variables play important roles in the prognostic evaluation and treatment decisions of DMGC patients. Accurate identification of LN status in DMGC patients is critical. LND performance is associated with increased survival and has clinical practicability.

\section{INTRODUCTION}

Lymph node (LN) metastasis is one of the most common outcomes for M0 gastric cancer (GC) patients [1-4]. However, its clinical impact on distant metastatic gastric cancer (DMGC) patients remains unclear. With advances in medical technologies, surgical therapies for distant metastases are gaining attention and are linked to survival benefits [5-7]. They enable LN dissection
(LND) and evaluation in DMGC patients. Therefore, it is important to determine whether accurate identification of LN metastatic status in DMGC patients is clinically worthwhile.

LN metastasis variables include $\mathrm{N}$ stage, $[8,9]$ positive LN (PLN) count, $[10,11]$ and $L N$ ratio (LNR), $[10,12-15]$ which refers to the ratio of the PLN count to the total number of LNs dissected. These variables have all been investigated as prognostic factors in $\mathrm{M} 0 \mathrm{GC}$ 
patients, but few studies have evaluated their prognostic value in patients with DMGC. Moreover, only 3 studies based on the Surveillance, Epidemiology, and End Results (SEER) database investigated the outcomes of DMGC, $[7,16,17]$ none of which systematically discussed the role of LND and LN metastatic status in the management of this disease.

The objective of the present study was to determine whether accurate identification of LN status in DMGC patients is of clinical value. We also evaluated the survival impact of LND and whether there is a minimum number of dissected LNs required to best predict overall status. To guarantee a sufficient follow-up period, our study included patients documented in the SEER database (which was administered by the National Cancer Institute) who were diagnosed between 2004 and 2009. This is the first report of its kind to be based on data extracted from the SEER database.

\section{RESULTS}

\section{Patient selection and clinicopathological characteristics of the entire cohort}

The patient selection schema is shown in Figure 1, and detailed patient characteristics are listed in Supplementary Table S1. Briefly, 1889 patients were included in this study. The median age at diagnosis was 65 years (range, 19-95 years). Median survival was 10 months and the 3-year survival rate (YSR) was $15.5 \%$. Data from $500(26.5 \%)$ patients were censored. LN dissection was performed in 1593 patients $(84.3 \%)$. The median number of LNs examined was 13 (range, 1-90+), the median PLN count was 7 (range, 0-79), and the median LNR was $66.7 \%$.

\section{Comparison of clinicopathological characteristics of the cohorts stratified by LND}

Supplementary Table S2 compares the clinicopathological variables between those who underwent LND $(n=1593)$ and those who did not $(n=272)$. Compared to patients who underwent LND, those who did not undergo dissection were more likely to have lower $\mathrm{N}$ stages as well as a tumor histology indicating unspecified carcinoma, advanced tumor extension, and metastasis involving organs or the peritoneum. There were no significant differences regarding other variables between the subgroups.

\section{Survival impact of N stage, PLN, and LNR}

The survival impact of $\mathrm{N}$ stage, PLN, and LNR are shown in Table 1, Table 2, and Figure 2. Concerning $\mathrm{N}$ stage (Table 1A), we found that DMGC patients with N0 stage had significantly better prognosis than non-N0 patients on univariate analysis (UVA). Such statistically significant differences were observed in all patients (Figure 2A) and in patients who underwent LND (Figure 2B) but not in those who did not $(P=0.206)$. Further analysis showed that, in patients who underwent LND, the prognosis of N0 patients was significantly more favorable than that of $\mathrm{N} 1$ patients, while $\mathrm{N} 1$ patients in turn had significantly better prognosis than N2 and N3 patients. There was no significant difference between N2 and N3 patients.

The LNR (Figure 2C, Table 1B) was negatively correlated with patients' median survival and 3-YSR. For binary classified LNR, cancer-specific survival (CSS) was more favorable in those with lower LNR values in all the cohorts we analyzed. For multi-category LNR (those who underwent LND, those with LN metastasis [N1-N3], and those of N1 stage), the median survival and 3-YSR significantly decreased as the LNR increased. In patients of $\mathrm{N} 2$ or N3 stage, a statistically significant difference was noted although it was not uniformly distributed.

When determining the prognostic significance of PLN and LNR by multivariate analysis (MVA) (Table 2), we found that the LNR was highly predictive of worse CSS in all patient categories, whereas PLN count was not.

\section{Correlations between the number of LNs examined, the PLN count, $N$ stage, and LNR}

Pearson's correlation analysis showed that the PLN count significantly correlated with the number of dissected LNs $(r=0.753, P<0.001$, Figure $3 \mathrm{~A})$, and there was a significant positive correlation between LNR and PLN count ( $r=0.540, P<0.001$, Figure 3B). However, no correlation between LNR and the LND number was observed ( $r=0.003, P=0.905$, Figure 3C). Furthermore, in the proportion of patients classified as N0, we found no significant difference between subgroups divided according to number of LNs examined ("15-30" vs. " $>30 ")(P=0.953)$, but the proportion of patients with N1, $\mathrm{N} 2$, and N3 stages increased significantly as the number of total LNs examined rose $(P<0.001)$.

\section{N stage migration}

Table 3 shows the analysis of the $\mathrm{N}$ stage migration effect. In M0 GC patients with the same number of positive nodes, prognosis may differ dramatically when the number of nodes examined is insufficient $(<15)$; this is referred to as the "stage migration effect" or "inappropriate understaging" [18, 19]. However, in DMGC patients, changes in the number of positive regional LNs merely alter $\mathrm{N}$ stage diagnosis but not overall staging according to the current AJCC pathologic tumor-node-metastasis (pTNM) system $[20,21]$. Therefore, it is necessary to determine whether the migration effect still applies to DMGC. 


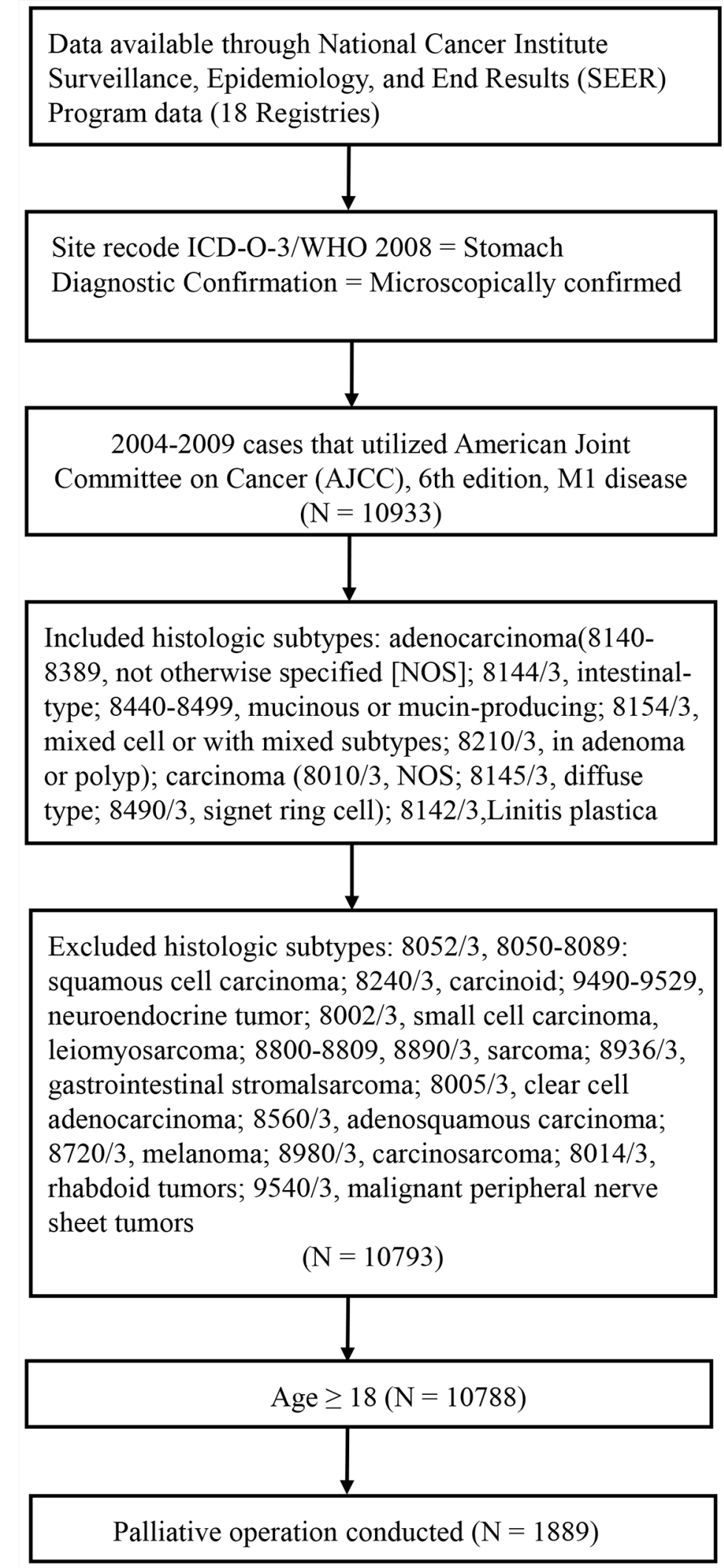

Figure 1: Selection of the distant metastatic gastric cancer patients included in the study. 
A

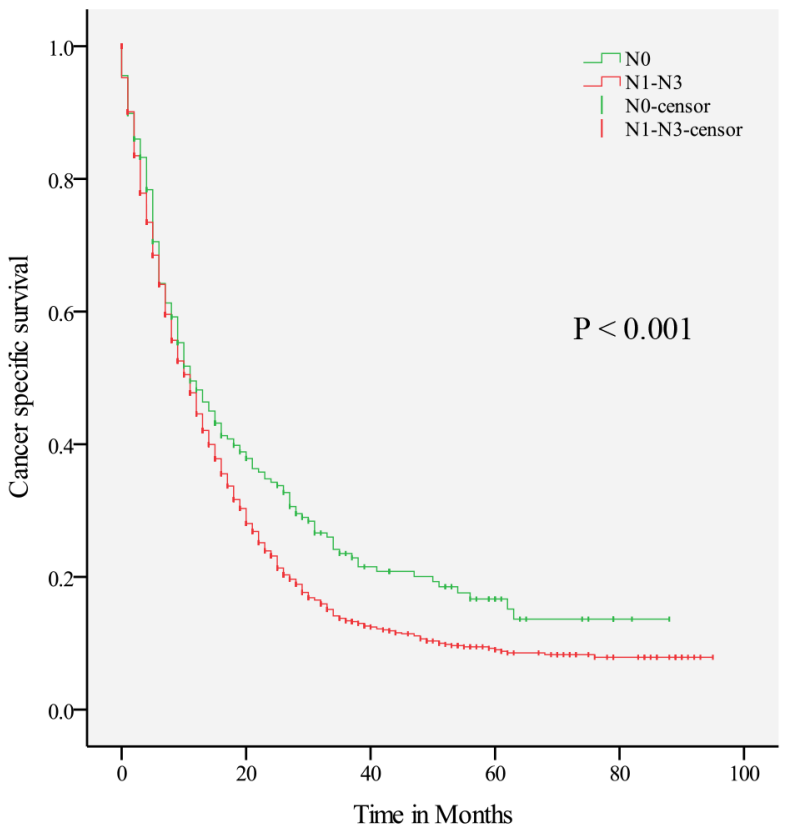

$\mathrm{C}$

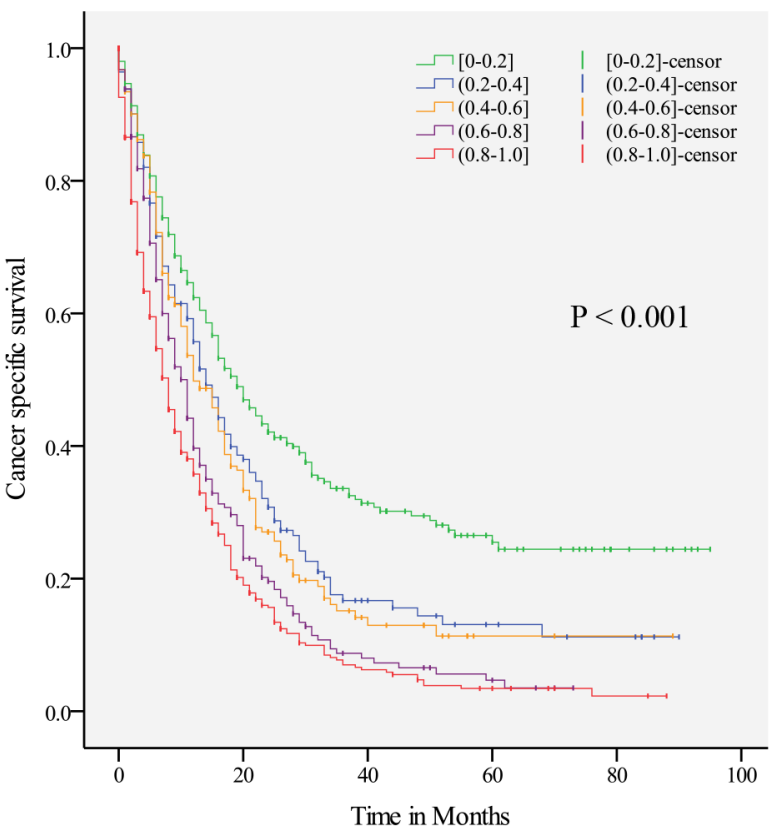

B

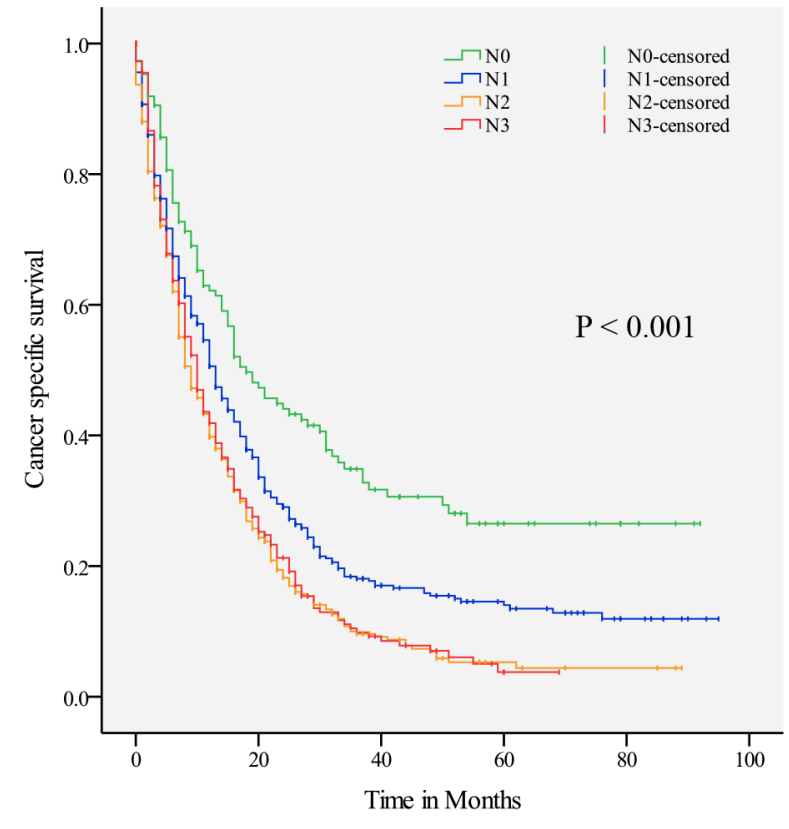

$\mathrm{D}$

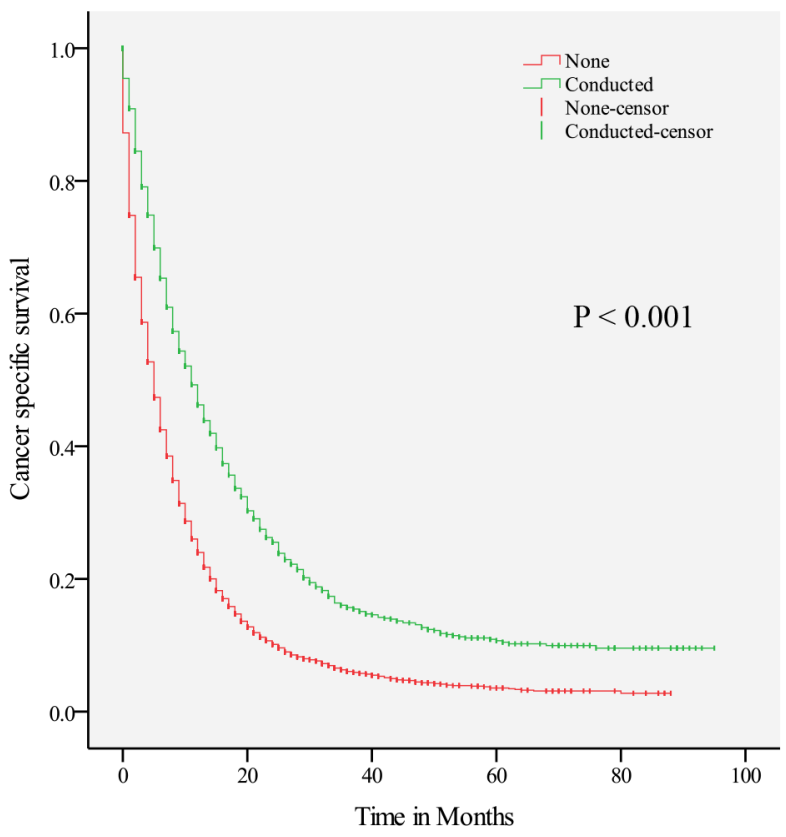

Figure 2: Kaplan-Meier curves of CSS by nodal metastatic status, N stage, lymph node ratio and undergoing of lymph node dissection. Figure 2 shows the comparison of actuarial cancer specific survival curves in distant metastatic gastric cancer (DMGC) patients according to nodal metastatic status, $\mathrm{N}$ stages, lymph node ratio (LNR), and undergoing of lymph node dissection (LND). A. Nodal metastatic status in all DMGC patients; B. N stage in patients with LND; C. LNR in patients who underwent LND; D. LND in all DMGC patients.

Since the Pearson's correlation and Chi-square tests revealed that the LND number could influence the PLN count and $\mathrm{N}$ stage diagnosis, we performed UVA
(Table 3A) and MVA (Table 3B) on N0, N1, and N2 stage patients to test the potential effect of $\mathrm{N}$ stage migration caused by LND as well as the number of dissections 
Table 1: Univariate analysis of the impact of metastatic lymph node variables on survival

A. Survival impact of $\mathrm{N}$ stages in all distant metastatic gastric cancer (DMGC) patients, DMGC patients without nodal dissection alone, and DMGC patients with nodal dissection alone.

\begin{tabular}{|c|c|c|c|c|c|c|c|c|c|}
\hline \multirow[t]{2}{*}{$\begin{array}{c}\text { Cohorts } \\
\text { of all patients }\end{array}$} & \multicolumn{3}{|c|}{ All patients } & \multicolumn{3}{|c|}{ Without LND } & \multicolumn{3}{|c|}{ With LND } \\
\hline & MS (m) & 3-YSR (\%) & $P$ & MS (m) & 3-YSR (\%) & $P$ & MS (m) & 3-YSR (\%) & $P$ \\
\hline \multicolumn{10}{|l|}{ N stage } \\
\hline N0 & 13.0 & 25.5 & Ref. & 9.0 & 13.0 & Ref. & 18.0 & 35.1 & Ref. \\
\hline $\mathrm{N} 1-\mathrm{N} 3$ & 10.0 & 14.2 & 0.000 & 7.0 & 5.1 & 0.206 & 11.0 & 14.6 & 0.000 \\
\hline N1 & 12.0 & 17.8 & 0.000 & 7.0 & 5.1 & 0.206 & 12.0 & 19.4 & 0.000 \\
\hline N2 & 9.0 & 10.6 & 0.036 & NA & NA & NA & 9.0 & 10.7 & 0.000 \\
\hline N3 & 10.0 & 11.2 & 0.011 & NA & NA & NA & 10.0 & 11.2 & 0.000 \\
\hline
\end{tabular}

Abbreviations: LND, lymph node dissection; MS, median survival; m, months; YSR, year survival rate; Ref, reference; NA, not applicable.

B. Survival impact of lymph node ratio in all DMGC patients with nodal dissection, patients with positive nodes, and patients of same $\mathrm{N}$ stages.

\begin{tabular}{|c|c|c|c|c|c|c|c|c|c|c|c|c|c|c|c|}
\hline \multirow{2}{*}{$\begin{array}{l}\text { Patients } \\
\text { with LND }\end{array}$} & \multicolumn{3}{|c|}{ All patients } & \multicolumn{3}{|c|}{ N1-N3 } & \multicolumn{3}{|c|}{ N1 } & \multicolumn{3}{|c|}{$\mathrm{N} 2$} & \multicolumn{3}{|c|}{ N3 } \\
\hline & MS (m) & $\begin{array}{c}\text { 3-YSR } \\
(\%)\end{array}$ & $P$ & MS (m) & $\begin{array}{c}\text { 3-YSR } \\
(\%)\end{array}$ & $P$ & MS (m) & $\begin{array}{c}\text { 3-YSR } \\
(\%)\end{array}$ & $P$ & MS (m) & $\begin{array}{c}\text { 3-YSR } \\
(\%)\end{array}$ & $P$ & MS (m) & $\begin{array}{c}\text { 3-YSR } \\
(\%)\end{array}$ & $P$ \\
\hline LNR & & & & & & 0.000 & & & & & & & & & \\
\hline$[0-0.2]$ & 19.0 & 34.0 & Ref & 19.0 & 32.3 & Ref. & 19.0 & 33.5 & Ref. & NA & NA & NA & NA & NA & NA \\
\hline$(0.2-0.4]$ & 14.0 & 18.6 & 0.002 & 14.0 & 18.8 & 0.014 & 13.0 & 20.0 & 0.015 & 16.0 & 13.5 & Ref. & NA & NA & NA \\
\hline$(0.4-0.6]$ & 12.0 & 16.4 & 0.000 & 12.0 & 16.4 & 0.002 & 12.0 & 14.6 & 0.006 & 12.0 & 14.0 & 0.503 & 18.0 & 30.8 & Ref. \\
\hline$(0.6-0.8]$ & 11.0 & 9.4 & 0.000 & 11.0 & 9.4 & 0.000 & 11.0 & 10.6 & 0.001 & 9.0 & 10.7 & 0.101 & 11.0 & 6.0 & 0.059 \\
\hline$(0.8-1.0]$ & 8.0 & 8.5 & 0.000 & 8.0 & 8.5 & 0.000 & 8.0 & 6.2 & 0.000 & 7.0 & 9.1 & 0.003 & 8.0 & 9.2 & 0.009 \\
\hline LNR & & & & & & 0.000 & & & & & & & & & \\
\hline$[0-0.6]$ & 16.0 & 24.7 & Ref. & 15.0 & 21.8 & Ref. & 15.0 & 24.3 & Ref. & 13.0 & 13.3 & Ref. & 21.0 & 32.7 & Ref. \\
\hline$(0.6-1]$ & 8.0 & 8.8 & 0.000 & 8.0 & 8.8 & 0.000 & 8.0 & 7.6 & 0.000 & 8.0 & 9.6 & 0.000 & 9.0 & 8.3 & 0.004 \\
\hline
\end{tabular}

Abbreviations: LND, lymph node dissection; MS, median survival; $m$, months; YSR, year survival rate; LNR, lymph node ratio; Ref, reference; NA, not applicable.

performed. For patients with N0 stage, undergoing LND correlated with better survival both in UVA and MVA. However, the number of LNs dissected was not an independent factor for favorable survival $(P=0.256)$. As we separately analyzed the risk factors for patients of $\mathrm{N} 1$ and N2 stages, having undergone LND and a higher number of dissections performed both correlated with increased survival in UVA and MVA.

\section{Survival impact of LND and number}

Since metastatic LN variables could predict prognosis, and a greater LND number was associated with a more accurate diagnosis of $\mathrm{N}$ stage, we inquired whether undergoing LND and experiencing a greater number of dissections are detrimental to survival owing to more operative complications. Thus, we conducted survival analyses in all DMGC patients as well as node-positive patients separately.

Compared with those who did not undergo LND, the median survival and 3-YSR were significantly better in patients who underwent LND among all DMGC patients on UVA (Figure 2D, Table 4). CSS improvements were also positively associated with the number of dissected LNs. In node-positive patients (Table 4), similar CSS outcomes were observed. Cox regression (Table 5) also revealed that undergoing $\operatorname{LND}(P=0.020)$ and a higher number of dissected LNs $(P<0.001)$ were associated with improved survival both in the entire cohort and in the LND subgroup alone. 
Table 2: Impact of positive lymph node count and lymph node ratio on survival in distant metastatic gastric cancer patients by multivariate analysis

\begin{tabular}{|c|c|c|c|c|c|c|c|c|c|c|}
\hline \multirow[t]{2}{*}{ Item } & \multicolumn{2}{|c|}{ All patients } & \multicolumn{2}{|c|}{ N1-N3 } & \multicolumn{2}{|c|}{ N1 } & \multicolumn{2}{|c|}{ N2 } & \multicolumn{2}{|c|}{ N3 } \\
\hline & HR & $95 \%$ CI & HR & $95 \%$ CI & HR & $95 \%$ CI & HR & $95 \%$ CI & HR & $95 \%$ CI \\
\hline Age $^{a}$ & $1.006^{*}$ & $1.001-1.010$ & $1.005^{*}$ & $1.000-1.010$ & \multicolumn{2}{|c|}{ NS } & \multicolumn{2}{|c|}{ NS } & \multicolumn{2}{|c|}{ NS } \\
\hline $\begin{array}{l}\text { T stage } \\
\text { (vs. T0-T2) }\end{array}$ & \multicolumn{2}{|r|}{ NS } & \multicolumn{2}{|c|}{ NS } & \multicolumn{2}{|c|}{ NS } & \multicolumn{2}{|c|}{ NS } & \multicolumn{2}{|c|}{ NA } \\
\hline $\begin{array}{l}\text { Grade } \\
\text { (vs. I-II) }\end{array}$ & $1.205^{*}$ & $1.017-1.429$ & \multicolumn{2}{|c|}{ NS } & \multicolumn{2}{|c|}{ NS } & \multicolumn{2}{|c|}{ NA } & \multicolumn{2}{|c|}{ NA } \\
\hline \multicolumn{11}{|l|}{$\begin{array}{l}\text { Tumor site } \\
\text { (vs. Body) }\end{array}$} \\
\hline Fundus & \multicolumn{2}{|r|}{ NS } & \multicolumn{2}{|c|}{ NS } & \multicolumn{2}{|c|}{ NA } & $2.733^{* *}$ & $\begin{array}{l}1.313- \\
5.688\end{array}$ & \multicolumn{2}{|c|}{ NA } \\
\hline \multicolumn{11}{|l|}{$\begin{array}{l}\text { Tumor } \\
\text { extent (vs. } \\
\text { Localized) }\end{array}$} \\
\hline Regional & \multicolumn{2}{|r|}{ NS } & \multicolumn{2}{|c|}{ NS } & \multicolumn{2}{|c|}{ NS } & $1.329^{*}$ & $\begin{array}{c}1.003- \\
1.761\end{array}$ & \multicolumn{2}{|c|}{ NS } \\
\hline $\begin{array}{l}\text { Further } \\
\text { extent }\end{array}$ & $1.605^{* *}$ & $1.215-2.120$ & $1.568 * *$ & $1.173-2.096$ & \multicolumn{2}{|c|}{ NS } & $1.695^{*}$ & $\begin{array}{l}1.062- \\
2.705\end{array}$ & $2.022^{*}$ & $\begin{array}{c}1.156- \\
3.534\end{array}$ \\
\hline \multicolumn{11}{|l|}{$\begin{array}{l}\text { Mets at diag } \\
\text { (vs. DNs) }\end{array}$} \\
\hline OPI & $1.266^{* *}$ & $1.061-1.511$ & \multicolumn{2}{|c|}{ NS } & \multicolumn{2}{|c|}{ NS } & \multicolumn{2}{|c|}{ NS } & \multicolumn{2}{|c|}{ NA } \\
\hline $\begin{array}{l}\text { OPI and } \\
\text { DNs }\end{array}$ & $1.326^{*}$ & $1.014-1.735$ & \multicolumn{2}{|c|}{ NS } & \multicolumn{2}{|c|}{ NS } & $\mathrm{N}$ & & & \\
\hline $\begin{array}{l}\text { Radi \& Surg } \\
\text { (vs. Surgery } \\
\text { alone) }\end{array}$ & $0.731^{* *}$ & $0.611-0.874$ & $0.663^{* *}$ & $0.547-0.804$ & $0.613^{* *}$ & $\begin{array}{c}0.460- \\
0.817\end{array}$ & $0.658^{* *}$ & $\begin{array}{c}0.482- \\
0.898\end{array}$ & & \\
\hline $\mathrm{PLN}^{\mathrm{a}}$ & 0.997 & $0.989-1.004$ & 0.997 & $0.989-1.004$ & 1.033 & $\begin{array}{c}0.973- \\
1.097\end{array}$ & 1.015 & $\begin{array}{c}0.971- \\
1.060\end{array}$ & 1.006 & $\begin{array}{c}0.993- \\
1.019\end{array}$ \\
\hline $\mathrm{LNR}^{\mathrm{a}}$ & $2.384^{* * *}$ & $1.920-2.960$ & $2.408^{* *}$ & $1.885-3.077$ & $2.123^{* *}$ & $\begin{array}{l}1.533- \\
2.941\end{array}$ & $2.241^{* *}$ & $\begin{array}{c}1.386- \\
3.624\end{array}$ & $5.640^{* *}$ & $\begin{array}{l}2.320- \\
14.264\end{array}$ \\
\hline
\end{tabular}

Survival was analyzed in all patients with nodal dissections, patients with positive nodes and patients of same $\mathrm{N}$ stages.

${ }^{a}$ Continuous variable

$* P<0.05$;

$* * P<0.01$.

Abbreviations: HR, hazard ratio; CI, confidence interval; Mets, metastasis status; diag, diagnosis; OPI, organs or peritoneal involved; DNs, distant nodes; PLN, positive lymph node; LNR, lymph node ratio; NA, not applicable; NS, not significance; Radi, radiation; Surg, surgery.

For node-positive patients, both LND $(P=0.004)$ and number of dissected nodes $(P<0.001)$ were significantly associated with postoperative survival benefits as well.

\section{DISCUSSION}

This is the first study to systematically evaluate the clinical implications of accurately identifying LN status in DMGC patients based on data from a large public database. Our data showed that obtaining LN metastasis status is crucial for DMGC patients.
On one hand, patients with N0 and N1 pathological diagnoses have a significant survival advantage. On the other hand, inclusion of radiation therapy, which was thought to have a significant survival benefit on locally advanced gastrointestinal cancer when combined with chemotherapy, [22, 23] had no significant impact on the survival in DMGC patients with N0 stage, and its therapeutic benefit was only apparent in patients with pathologically confirmed positive metastatic LNs based on our data (Supplementary Table S3). Therefore, accurate identification of positive nodes in patients with 

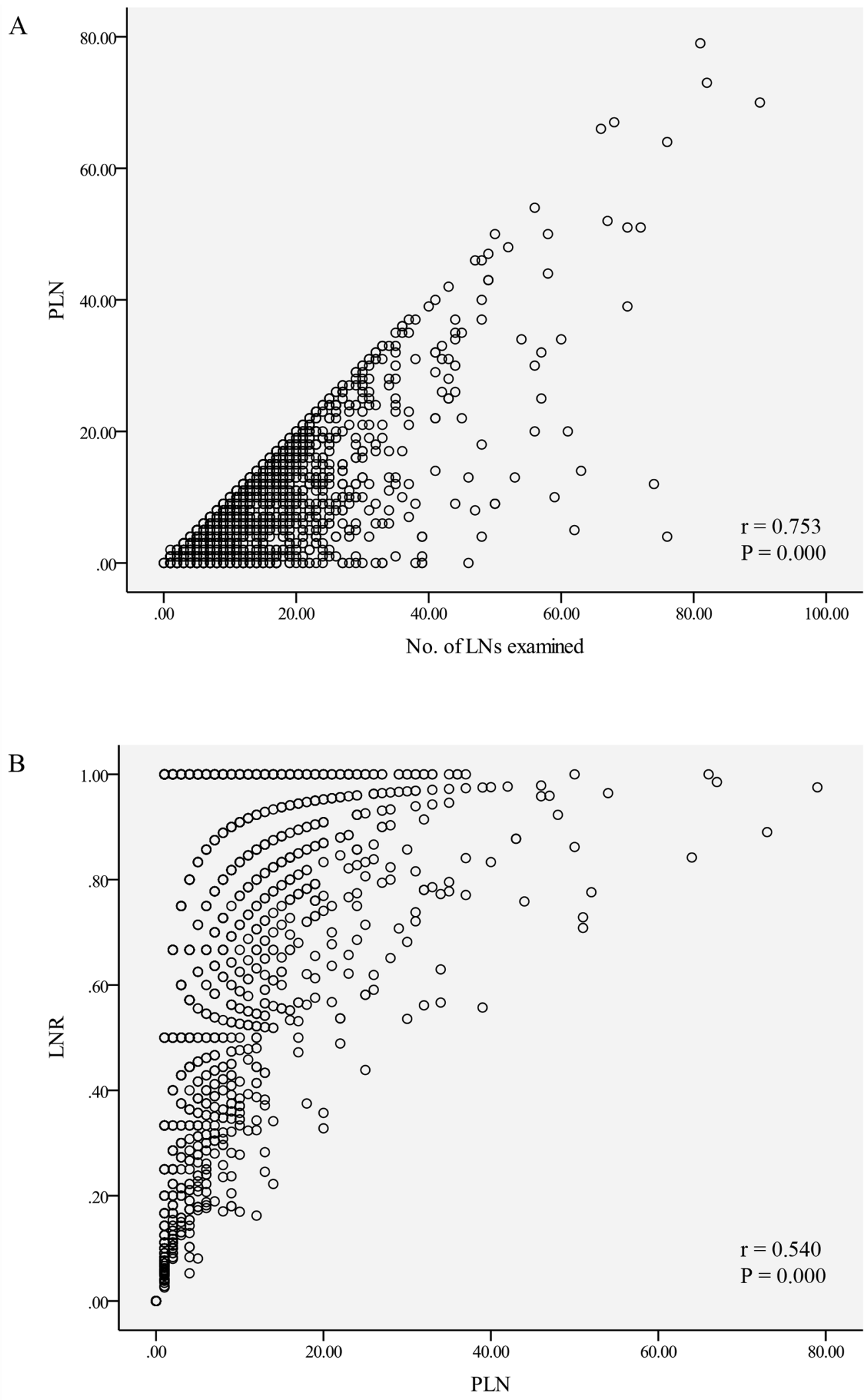

Figure 3: The correlation between number of LNs examined, positive lymph node count and lymph node ratio. The scatter plots demonstrate the correlation between the number of lymph nodes (LNs) examined, positive lymph node (PLN) count, and lymph node ratio (LNR). A. Positive correlation between PLN counts and the number of LNs examined $(r=0.753, P<0.001)$; B. Positive correlation between the LNR and PLN counts $(r=0.540, P<0.001)$. (Continued) 


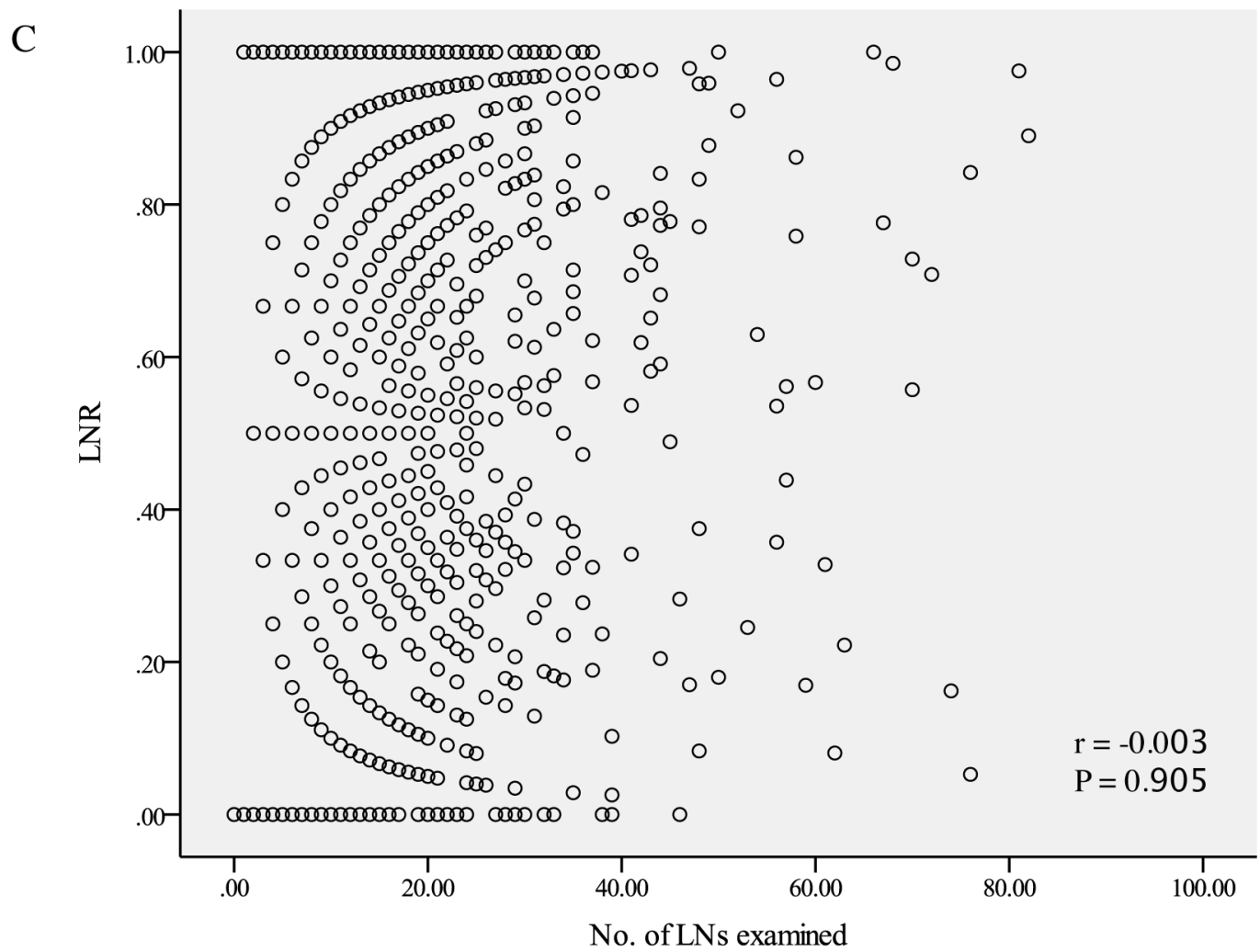

Figure 3: (Continued) The correlation between number of LNs examined, positive lymph node count and lymph node ratio. C. No significant correlation exists between LNR and the number of LNs examined $(r=-0.003, P=0.905)$.

DMGC should be considered essential for treatment guidance.

The number of dissected LNs was considered a main factor contributing to staging accuracy in M0 patients. However, in DMGC patients, we also found that examining fewer LNs could result in understaging of the $N$ category. Furthermore, the Chi-square test revealed that a minimum of 15 LNs should be examined for an accurate identification of positive metastatic nodes, and a higher number of LNs examined was linked with more accurate $\mathrm{N}$ stage classification. This finding is consistent with AJCC recommendation for curative GC, which states that $>15$ LNs should be evaluated for correct classification under the current TNM staging system. [20]

To further explore $\mathrm{N}$ stage migration as a confounding factor for survival analysis, MVA was performed on N0, N1, and N2 stage subgroups. Our results suggested that LND administration and number were both important confounders of survival analysis, especially in patients with the same positive nodal stages; this may have been caused by $\mathrm{N}$ stage misclassification.

Extended lymphadenectomy is regarded to have a therapeutic benefit for regional disease control in M0 patients. [19, 24] However, resection of more LNs may cause expanded tissue damage. Therefore, determining of whether undergoing LND and greater LND numbers can increase patients' mortality rates would help expose the utility of LND in clinical practice. In order to explore the potential survival impact of performing LND in DMGC patients, we analyzed the impact of undergoing LND as well as the number of dissections on CSS in the entire dataset, as well as in patients with positive metastatic node. We observed a better CSS associated with LND administration and a greater number of dissected LNs. LND administration and number were both independent prognostic factors in DMGC patients. This further illustrated the necessity and prudence of using LND information in DMGC patients who underwent palliative surgery.

Several reports $[10,13,25-27]$ revealed that, compared to $\mathrm{N}$ stage and absolute PLN number, LNR is a more accurate prognostic indicator in M0 GC patients. In this study, we also demonstrated that LNR was superior to PLN and N stage, not only because LNR was an independent prognostic predictor while PLN was not, but also because LNR better discriminated patients' prognostic risk profiles in those of the same $\mathrm{N}$ stage. Additionally, we found that the LNR value could be used as a potent predictor of metastatic status of patients' overall LNs regardless of the total number of LNs examined, based on Pearson correlation test results. These data indicated that LNR is a more practical 
Table 3: N stage migration analysis. Survival impact of undergoing lymph node dissection and the number of dissections in N0, N1, and N2 stage in distant metastatic gastric cancer patients.

\section{A. Univariate analysis}

\begin{tabular}{|c|c|c|c|c|c|c|c|c|c|}
\hline \multirow{2}{*}{$\begin{array}{l}\text { UVA } \\
\text { Factor }\end{array}$} & \multicolumn{3}{|c|}{ No } & \multicolumn{3}{|c|}{ N1 } & \multicolumn{3}{|c|}{ N2 } \\
\hline & MS (m) & $\begin{array}{c}\text { 3-YSR } \\
(\%)\end{array}$ & $P$ & MS (m) & $\begin{array}{c}\text { 3-YSR } \\
(\%)\end{array}$ & $P$ & MS (m) & $\begin{array}{c}\text { 3-YSR } \\
(\%)\end{array}$ & $P$ \\
\hline LND & & & 0.000 & & & 0.001 & & NA & \\
\hline $\begin{array}{l}\text { Not } \\
\text { performed }\end{array}$ & 9.0 & 12.9 & Ref. & 7.0 & 4.2 & Ref. & & NA & \\
\hline Performed & 19.0 & 35.6 & 0.000 & 13.0 & 18.9 & 0.001 & 10.0 & 11.3 & NA \\
\hline \multicolumn{10}{|l|}{$\begin{array}{l}\text { LND } \\
\text { number }\end{array}$} \\
\hline $1-6$ & 16.0 & 21.2 & 0.037 & 7.0 & 11.3 & 0.059 & \multicolumn{3}{|c|}{ NA } \\
\hline $7-15$ & 23.0 & 46.1 & 0.000 & 11.0 & 19.7 & 0.000 & 8.0 & 8.7 & Ref. \\
\hline $16-30$ & 31.0 & 38.4 & 0.001 & 13.0 & 30.5 & 0.000 & 10.0 & 14.3 & 0.015 \\
\hline $31+$ & NA & 65.8 & 0.001 & 17.0 & 57.3 & 0.000 & 21.0 & 3.7 & 0.100 \\
\hline
\end{tabular}

Abbreviations: UVA, univariate analysis; MS, median survival; m, months; YSR, year survival rate; LND, lymph node dissection; NA, not applicable; Ref, reference.

\section{B. Multivariate analysis}

\begin{tabular}{|c|c|c|c|c|c|c|}
\hline \multirow{2}{*}{$\begin{array}{l}\text { MVA } \\
\text { Factor }\end{array}$} & \multicolumn{2}{|c|}{ No } & \multicolumn{2}{|c|}{ N1 } & \multicolumn{2}{|c|}{ N2 } \\
\hline & HR & $95 \%$ CI & HR & $95 \%$ CI & HR & $95 \%$ CI \\
\hline \multicolumn{7}{|l|}{ All patients } \\
\hline $\begin{array}{l}\text { LND (vs. Not } \\
\text { Performed) }\end{array}$ & $0.608 * *$ & $0.422-0.875$ & $0.590 * *$ & $0.418-0.832$ & \multicolumn{2}{|c|}{ NA } \\
\hline \multicolumn{7}{|l|}{$\begin{array}{l}\text { Patients with } \\
\text { LND }\end{array}$} \\
\hline LND number ${ }^{\mathrm{a}}$ & 0.983 & $0.954-1.013$ & $0.963 * *$ & $0.947-0.978$ & $0.981 * *$ & $0.966-0.995$ \\
\hline
\end{tabular}

${ }^{a}$ Continuous variable

$* * P<0.01$

Abbreviations: MVA, multivariate analysis; HR, hazard ratio; CI, confidence interval; LND, lymph node dissection; NA, not applicable.

and suitable clinical prognostic indicator in DMGC patients than $\mathrm{N}$ stage.

There is no consensus on an optimal cut-off value for LNR. In the present study, the mean LNR was 0.59; hence, we assigned 0.6 as the cut-off value. However, we also evaluated LNR at incremental cut-off points $(0.2,0.4,0.6$, and 0.8$)$, and found that survival decreased significantly as the cut-off point increased. Therefore, whether these LNR classification methods are appropriate in patients with DMGC requires further evaluation in a larger, prospective, randomized clinical trial.

The limitations of our study, aside from potential selection bias because of its retrospective nature, were mostly associated with the use of the SEER registry.
First, the exact LND number depended on accurate identification of LNs in the resected specimen. However, because $\mathrm{N}$ stage does not correlate with overall staging for M1 patients, it is unknown whether diagnosing pathologists would have identified as many LNs as possible, as would be the case for M0 patients. Second, several aspects of pathology-specific covariates critical for survival evaluation, such as perineural invasion and vascular invasion, were missing from the SEER database. The effect that these variables have on outcomes may obfuscate that of LN parameters evaluated in the present study. Third, palliative chemotherapy is one of the most important prognostic factors. Since systemic chemotherapy for 
Table 4: Survival impact of lymph node dissection according to univariate analysis

\begin{tabular}{|c|c|c|c|c|c|c|}
\hline \multirow[t]{2}{*}{ Factor } & \multicolumn{3}{|c|}{ All patients } & \multicolumn{3}{|c|}{ Patients with positive nodes } \\
\hline & MS (m) & $3-Y S R(\%)$ & $P$ & MS (m) & 3-YSR (\%) & $\boldsymbol{P}$ \\
\hline \multicolumn{7}{|l|}{ LND } \\
\hline Not performed & 8.0 & 8.1 & Ref. & 7.0 & 4.1 & Ref. \\
\hline Performed & 11.0 & 16.8 & 0.000 & 11.0 & 14.5 & 0.009 \\
\hline \multicolumn{7}{|l|}{ LND number } \\
\hline $1-6$ & 12.0 & 13.9 & 0.003 & 11.0 & 11.3 & 0.040 \\
\hline $7-15$ & 10.0 & 17.6 & 0.000 & 10.0 & 14.0 & 0.013 \\
\hline $16-30$ & 11.0 & 17.2 & 0.000 & 11.0 & 15.9 & 0.002 \\
\hline $31+$ & 15.0 & 19.4 & 0.000 & 14.0 & 16.6 & 0.000 \\
\hline
\end{tabular}

Survival impact of undergoing lymph node dissection and the number of dissections as determined by univariate analysis in all distant metastatic gastric cancer patients, and patients with positive nodes.

Abbreviations: LND, lymph node dissection; MS, median survival; m, months; YSR, year survival rate; Ref, reference.

DMGC patients is mandatory, we assumed that all patients underwent systemic chemotherapy, although this information was not included in the SEER registry. Fourth, the heterogeneity of the SEER population would also call for cautious interpretation. Healthier patients with better prognoses were more likely to receive locoregional treatments. Moreover, the outcome of lymphadenectomy depends on the experience of the surgeons across different institutions. Accordingly, data obtained by surgeons at high-volume institutions could be overrepresented in the dataset. Despite these limitations, we are still confident that our findings elucidated the clinical significance of accurate identification of LN status and LNR in DMGC.

In conclusion, proper determination of LN metastatic status by LND is of high clinical significance. At least $15 \mathrm{LNs}$ should be evaluated for precise identification for node-positive patients, and as many LNs as possible should be removed and examined to avoid $N$ stage migration and improved regional disease control. Since there are no randomized data to validate this finding to date, and because other relevant patient-stratifying data are missing from the SEER database, caution must be exercised before applying LND for the management of DMGC patients. However, our findings provide an important basis to initiate well-controlled prospective clinical trials that could address the role of LND in DMGC patients in a more definitive fashion. Moreover, LNR was superior to PLN count as a prognostic predictor. Classification according to LNR can avoid $\mathrm{N}$ stage migration related to the AJCC staging system. Clinically, using LNR can better stratify survival of surgically treated patients with DMGC, reducing the number of LNs needed for accurate staging.

\section{MATERIALS AND METHODS}

\section{Data collection and patient inclusion criteria}

Data were obtained from the publicly available version of the SEER database released in April 2014, which consisted of 18 population-based cancer registries covering approximately $27.8 \%$ of the population of the United States. The National Cancer Institute's SEER*Stat software (Surveillance Research Program, National Cancer Institute SEER*Stat software, www.seer.cancer. gov/seerstat; Version 8.1.5) was used to access the database. Detailed patient inclusion and exclusion criteria are shown in Figure 1.

\section{Demographic and clinicopathological variables}

Patients' demographic and clinicopathological variables, including 13 factors, were retrieved from the SEER database. The LNR was calculated by dividing the number of positive LNs by the total number of LNs dissected when at least $1 \mathrm{LN}$ was examined. Among these factors, sex, race, tumor grade, histologic type, $\mathrm{T}$ or $\mathrm{N}$ stage, primary site, tumor extension, tumor metastatic status, and treatment type were considered categorical variables. Continuous variables including age, LND number, and LN variables (PLN and LNR) were binned or categorized. The subgroups created from the binning of these variables are shown in Supplementary Table S4.

\section{Follow-up and survival endpoints}

The primary endpoint in this study was gastric CSS, defined as the period from diagnosis to death due to GC. 
Table 5: Survival impact of lymph node dissection according to multivariate analysis

\begin{tabular}{|c|c|c|c|c|c|c|c|c|}
\hline \multirow[t]{3}{*}{ Item } & \multicolumn{4}{|c|}{ All patients } & \multicolumn{4}{|c|}{ Patients with positive nodes } \\
\hline & \multicolumn{2}{|c|}{ All patients } & \multicolumn{2}{|c|}{ With LND } & \multicolumn{2}{|c|}{ All patients } & \multicolumn{2}{|c|}{ With LND } \\
\hline & HR & $95 \% \mathrm{CI}$ & HR & $95 \% \mathrm{CI}$ & HR & $95 \% \mathrm{CI}$ & HR & $95 \% \mathrm{CI}$ \\
\hline Age $^{a}$ & $1.005^{*}$ & $\begin{array}{l}1.001- \\
1.009\end{array}$ & $1.005^{*}$ & $\begin{array}{c}1.000- \\
1.010\end{array}$ & \multicolumn{2}{|c|}{ NS } & \multicolumn{2}{|c|}{ NS } \\
\hline $\begin{array}{l}\text { T stage } \\
\text { (vs. T0-T2) }\end{array}$ & $1.276^{* *}$ & $\begin{array}{l}1.115- \\
1.461\end{array}$ & \multicolumn{2}{|c|}{ NS } & $1.202 *$ & $\begin{array}{c}1.037- \\
1.392\end{array}$ & \multicolumn{2}{|c|}{ NS } \\
\hline $\begin{array}{l}\text { Grade } \\
\text { (vs. I-II) }\end{array}$ & $1.261^{* *}$ & $\begin{array}{l}1.085- \\
1.464\end{array}$ & $1.222^{*}$ & $\begin{array}{c}1.031- \\
1.448\end{array}$ & $1.250^{*}$ & $\begin{array}{c}1.053- \\
1.483\end{array}$ & \multicolumn{2}{|c|}{ NS } \\
\hline \multicolumn{9}{|l|}{$\begin{array}{l}\text { Tumor } \\
\text { extent (vs. } \\
\text { Localized) }\end{array}$} \\
\hline Further extent & $1.459^{* *}$ & $\begin{array}{l}1.155- \\
1.843\end{array}$ & $1.616^{* *}$ & $\begin{array}{c}1.223- \\
2.134\end{array}$ & $1.589 * *$ & $\begin{array}{c}1.214- \\
2.080 \\
\end{array}$ & $1.583 * *$ & $1.184-2.116$ \\
\hline \multicolumn{9}{|l|}{$\begin{array}{l}\text { Mets at diag } \\
\text { (vs. DNs) }\end{array}$} \\
\hline OPI & $1.326^{* *}$ & $\begin{array}{l}1.125- \\
1.562\end{array}$ & $1.255^{* *}$ & $\begin{array}{c}1.052- \\
1.496\end{array}$ & $1.198^{*}$ & $\begin{array}{l}1.006- \\
1.427\end{array}$ & & NS \\
\hline OPI and DNs & $1.433^{* *}$ & $\begin{array}{l}1.132- \\
1.813\end{array}$ & \multicolumn{2}{|c|}{ NS } & $1.405^{* *}$ & $\begin{array}{c}1.088- \\
1.815\end{array}$ & \multicolumn{2}{|c|}{ NS } \\
\hline $\begin{array}{l}\text { Radi \& } \\
\text { Surgery } \\
\text { (vs. Surgery } \\
\text { alone) }\end{array}$ & $0.724 * *$ & $\begin{array}{c}0.615- \\
0.853\end{array}$ & $0.709 * *$ & $\begin{array}{c}0.593- \\
0.848\end{array}$ & $0.637 * *$ & $\begin{array}{c}0.530- \\
0.766\end{array}$ & $0.644 * *$ & $0.531-0.781$ \\
\hline $\begin{array}{l}\text { LND (vs. Not } \\
\text { performed }\end{array}$ & $0.811^{*}$ & $\begin{array}{l}0.680- \\
0.967\end{array}$ & \multicolumn{2}{|c|}{ NA } & $0.628 * *$ & $\begin{array}{c}0.456- \\
0.864\end{array}$ & \multicolumn{2}{|c|}{ NA } \\
\hline $\mathbf{L N D}^{\mathrm{a}}$ & \multicolumn{2}{|c|}{ NA } & $0.969^{* *}$ & $\begin{array}{c}0.959 \\
0.978\end{array}$ & \multicolumn{2}{|c|}{ NA } & $0.969 * *$ & $0.960-0.979$ \\
\hline $\mathbf{P L N}^{\mathrm{a}}$ & \multicolumn{2}{|c|}{ NA } & $1.041^{* *}$ & $\begin{array}{c}1.029 \\
1.052\end{array}$ & \multicolumn{2}{|c|}{ NA } & $1.037^{* *}$ & $1.025-1.050$ \\
\hline
\end{tabular}

Survival impact of undergoing lymph node dissection and the number of dissections as determined by multivariate analysis in all distant metastatic gastric cancer patients, and patients with positive nodes.

${ }^{a}$ Continuous variable

$* P<0.05$

$* * P<0.01$

Abbreviations: HR, hazard ratio; CI, confidence interval; LND, lymph node dissection; PLN, positive lymph node; NA, not applicable; NS, not significance; Mets, metastasis status; diag, diagnosis; OPI, organs or peritoneal involved; DNs, distant nodes; Radi, radiation; Surg, surgery.

Data of patients who died from other causes or who were alive on the date of their last follow-up were censored.

\section{Statistical analyses}

A comparison of the categorical variables between LND subgroups was conducted using Pearson's $\chi^{2}$ test. Continuous variables were compared using the Students $t$-test. Pearson's correlation coefficient was used to study the relationships between PLN count, LNs examined number, and LNR. The Kaplan-Meier method [28] was used to calculate the actual survival rate and to plot survival curves, followed by the log-rank test [29] for UVA. MVAs were performed using the Cox regression model with stepwise regression. [30] Of note, LND number, PLN count, LNR, and patient age, which were analyzed as categorical variables on UVA, were considered continuous variables in the multivariate model. Categorical factors found to 
be significant $(P<0.05)$ in the UVA (Supplementary Table S3, S5-S6) combined with the above-mentioned continuous variables were analyzed using MVA. The LND number and PLN count were combined to determine the survival impact of undergoing LND as well as the number of dissections performed, whereas PLN and LNR were included simultaneously to determine which were independent survival predictors. Hazard ratios (HRs) and $95 \%$ confidence intervals were calculated, with an HR of $<1.0$ indicating survival benefit. $\mathrm{N}$ stage was not included in MVA because it was simply a manifestation of incremental PLN counts. All statistical analyses were performed using SPSS ver.19.0 (SPSS Inc., Chicago, IL), and a value of $P<$ 0.05 indicated statistical significance.

\section{ACKNOWLEDGMENTS AND FUNDING}

The authors thank the members of W. Liao's laboratory for valuable advice and discussions.

\section{CONFLICTS OF INTEREST}

The views expressed in our submitted article are of our own, not an official position of the institution or funder. We declare that there are no conflicts of interest associated with the publication of this manuscript.

\section{FINANCIAL SUPPORT}

This work was supported by the National Natural Science Foundation of China (Nos. 31271564 and 81472314 to Wangjun Liao), the Special Foundation for National Clinical Specialties of China (to The Department of Oncology, Nanfang Hospital), and the Team Program of Natural Science Foundation of Guangdong Province, China (No. S2011030003134).

\section{REFERENCES}

1. Dixon M, Mahar AL, Helyer LK, Vasilevska-Ristovska J, Law C, Coburn NG. Prognostic factors in metastatic gastric cancer: results of a population-based, retrospective cohort study in Ontario. Gastric cancer : official journal of the International Gastric Cancer Association and the Japanese Gastric Cancer Association. 2014.

2. Roder JD, Bottcher K, Siewert JR, Busch R, Hermanek P, Meyer HJ. Prognostic factors in gastric carcinoma. Results of the German Gastric Carcinoma Study 1992. Cancer. 1993; 72:2089-2097.

3. Li Q, Li G, Palmer JD, Zhang Z. Lymph Node Burden as a Predictive Factor for Selective Chemoradiotherapy in Patients With Locally Advanced Gastric Cancer After a D2 Dissection: A Retrospective Study. American journal of clinical oncology. 2014.
4. Toth D, Torok M, Kincses Z, Damjanovich L. Prospective, comparative study for the evaluation of lymph node involvement in gastric cancer: Maruyama computer program versus sentinel lymph node biopsy. Gastric cancer : official journal of the International Gastric Cancer Association and the Japanese Gastric Cancer Association. 2013; 16:201-207.

5. Yoshida K, Yamaguchi K, Okumura N, Osada S, Takahashi T, Tanaka Y, Tanabe K, Suzuki T. The roles of surgical oncologists in the new era: minimally invasive surgery for early gastric cancer and adjuvant surgery for metastatic gastric cancer. Pathobiology : journal of immunopathology, molecular and cellular biology. 2011; 78:343-352.

6. Bozzetti F, Bonfanti G, Audisio RA, Doci R, Dossena G, Gennari L, Andreola S. Prognosis of patients after palliative surgical procedures for carcinoma of the stomach. Surgery, gynecology \& obstetrics. 1987; 164:151-154.

7. Shridhar R, Almhanna K, Hoffe SE, Fulp W, Weber J, Chuong MD, Meredith KL. Increased survival associated with surgery and radiation therapy in metastatic gastric cancer: a Surveillance, Epidemiology, and End Results database analysis. Cancer. 2013; 119:1636-1642.

8. Reim D, Loos M, Vogl F, Novotny A, Schuster T, Langer R, Becker K, Hofler H, Siveke J, Bassermann F, Friess H, Schuhmacher C. Prognostic implications of the seventh edition of the international union against cancer classification for patients with gastric cancer: the Western experience of patients treated in a single-center European institution. Journal of clinical oncology. 2013; 31:263-271.

9. Sun Z, Wang ZN, Zhu Z, Xu YY, Xu Y, Huang BJ, Zhu GL, Xu HM. Evaluation of the seventh edition of American Joint Committee on Cancer TNM staging system for gastric cancer: results from a Chinese monoinstitutional study. Annals of surgical oncology. 2012; 19:1918-1927.

10. Ke B, Song XN, Liu N, Zhang RP, Wang CL, Liang H. Prognostic value of the lymph node ratio in stage III gastric cancer patients undergoing radical resection. PloS one. 2014; 9:e96455.

11. Kodera Y, Yamamura Y, Shimizu Y, Torii A, Hirai T, Yasui K, Morimoto T, Kato T, Kito T. The number of metastatic lymph nodes: a promising prognostic determinant for gastric carcinoma in the latest edition of the TNM classification. Journal of the American College of Surgeons. 1998; 187:597-603.

12. Lee SR, Kim HO, Son BH, Shin JH, Yoo CH. Prognostic significance of the metastatic lymph node ratio in patients with gastric cancer. World journal of surgery. 2012; 36:1096-1101.

13. XuDZ, Geng QR, Long ZJ,Zhan YQ,LiW, ZhouZW, Chen YB, Sun XW, Chen G, Liu Q. Positive lymph node ratio is an independent prognostic factor in gastric cancer after $\mathrm{d} 2$ resection regardless of the examined number of lymph nodes. Annals of surgical oncology. 2009; 16:319-326. 
14. Zhou Y, Zhang J, Cao S, Li Y. The evaluation of metastatic lymph node ratio staging system in gastric cancer. Gastric cancer. 2013; 16:309-317.

15. Wang J, Dang P, Raut CP, Pandalai PK, Maduekwe UN, Rattner DW, Lauwers GY, Yoon SS. Comparison of a lymph node ratio-based staging system with the 7th AJCC system for gastric cancer: analysis of 18,043 patients from the SEER database. Annals of surgery. 2012; 255:478-485.

16. Yang D, Hendifar A, Lenz C, Togawa K, Lenz F, Lurje G, Pohl A, Winder T, Ning Y, Groshen S, Lenz HJ. Survival of metastatic gastric cancer: Significance of age, sex and race/ ethnicity. Journal of gastrointestinal oncology. 2011; 2:77-84.

17. Wang SJ, Emery R, Fuller CD, Kim JS, Sittig DF, Thomas CR. Conditional survival in gastric cancer: a SEER database analysis. Gastric cancer. 2007; 10:153-158.

18. Kong SH, Lee HJ, Ahn HS, Kim JW, Kim WH, Lee KU, Yang HK. Stage migration effect on survival in gastric cancer surgery with extended lymphadenectomy: the reappraisal of positive lymph node ratio as a proper N-staging. Annals of surgery. 2012; 255:50-58.

19. Smith DD, Schwarz RR, Schwarz RE. Impact of total lymph node count on staging and survival after gastrectomy for gastric cancer: data from a large US-population database. Journal of clinical oncology. 2005; 23:7114-7124.

20. Sobin LH GM, Wittekind C. TNM Classification of Malignant Tumours. Wiley Weinheim, Germany, (7th edition). 2010: 455.

21. Greene FL PD, Fleming ID, et al. AJCC Cancer Staging Handbook: TNM Classification of Malignant Tumors. 6th edition. New York, NY: Springer-Verlag; 2002.

22. Moertel CG, Gunderson LL, Mailliard JA, McKenna PJ, Martenson JA Jr., Burch PA, Cha SS. Early evaluation of combined fluorouracil and leucovorin as a radiation enhancer for locally unresectable, residual, or recurrent gastrointestinal carcinoma. The North Central Cancer Treatment Group. Journal of clinical oncology. 1994; 12:21-27.

23. Moertel CG, Childs DS Jr., Reitemeier RJ, Colby MY Jr., Holbrook MA. Combined 5-fluorouracil and supervoltage radiation therapy of locally unresectable gastrointestinal cancer. Lancet. 1969; 2:865-867.

24. Schwarz RE, Smith DD. Clinical impact of lymphadenectomy extent in resectable gastric cancer of advanced stage. Annals of surgical oncology. 2007; 14:317-328.

25. Huang CM, Lin JX, Zheng CH, Li P, Xie JW, Lin BJ, Wang JB. Prognostic impact of metastatic lymph node ratio on gastric cancer after curative distal gastrectomy. World journal of gastroenterology: WJG. 2010; 16:2055-2060.

26. Valsangkar NP, Bush DM, Michaelson JS, Ferrone CR, Wargo JA, Lillemoe KD, Fernandez-del Castillo C, Warshaw AL, Thayer SP. N0/N1, PNL, or LNR? The effect of lymph node number on accurate survival prediction in pancreatic ductal adenocarcinoma. Journal of gastrointestinal surgery. 2013; 17:257-266.

27. Chen S, Zhao BW, Li YF, Feng XY, Sun XW, Li W, Zhou ZW, Zhan YQ, Qian CN, Chen YB. The prognostic value of harvested lymph nodes and the metastatic lymph node ratio for gastric cancer patients: results of a study of 1,101 patients. PloS one. 2012; 7:e49424.

28. Kaplan EL MP. Nonparametric estimation from incomplete observations. J Am Stat Assoc. 1958; 53:457-481.

29. Peto RP . Conservatism in the approximation $\mathrm{E}(0-\mathrm{E}) 2 / \mathrm{E}$ in the log rank test for survival data or tumor incidence data. Biometrics. 1973; 29:579-584.

30. DR C. Regression models and life tables. J R Stat Soc B. 1972; 34:187-220. 